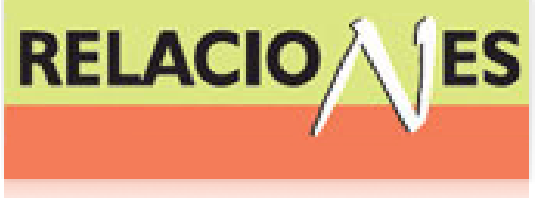

Relaciones. Estudios de historia y sociedad ISSN: 0185-3929

relacion@colmich.edu.mx

El Colegio de Michoacán, A.C

México

Baños Ramírez, Othón

Piratería forestal y economía-mundo: El caso de la Laguna (1558-1717)

Relaciones. Estudios de historia y sociedad, vol. XXXIII, núm. 132, 2012, pp. 75-107

El Colegio de Michoacán, A.C

Zamora, México

Disponible en: http://www.redalyc.org/articulo.oa?id=13725134003

- Cómo citar el artículo

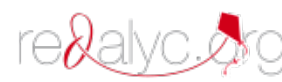

- Número completo

- Más información del artículo

Página de la revista en redalyc.org

Sistema de Información Científica

Red de Revistas Científicas de América Latina, el Caribe, España y Portugal Proyecto académico sin fines de lucro, desarrollado bajo la iniciativa de acceso abierto 


\title{
Piratería forestal y economía-mundo: El caso de la Laguna (1558-1717)
}

\author{
Othón Baños Ramírez* \\ UNIVERSIDAD AUTÓNOMA DE YUCATÁN
}

La piratería observada en el Caribe y en el Golfo de México es un fenómeno histórico complejo. Duró más de dos siglos y se reconocen varias etapas. Se distinguen dos modalidades, la del acecho y asalto a los barcos y la del asalto y saqueo a las poblaciones costeras. En este trabajo se reconoce una tercera modalidad practicada en la región de la Laguna, Campeche, México, basada en la lógica del mercado y la ganancia obtenida a través del trabajo de los participantes en el corte y tráfico del palo de tinte. Diferente en muchos sentidos al contrabando también común en esa época.

(Pirateria, Economía-mundo, Caribe, palo de tinte, la Laguna de Campeche)

"Corsarios británicos sorprendieron su abandono y se apoderaron de ella". Ignacio Rubio Mañé, 1953.

\section{INTRODUCCIÓN}

asi desde el momento en que aparecieron en esta región del mundo los piratas asediaron la península de Yucatán. La piratería que tuvo lugar en el Caribe y en el Golfo de México duró más de dos siglos con sus respectivas variantes. Es un fenómeno fascinante y complejo, ampliamente estudiado. No dispongo de nuevas evidencias para ampliar o modificar las historias ya bien conocidas. La idea del presente trabajo es sugerir una interpretación económica de las actividades de "los piratas de la Laguna", cuyo móvil era la obtención de una substancia llamada hematoxilina. ${ }^{1}$

*bramirez@uady.mx Quiero agradecer la valiosa colaboración de Diana Mayanín Belmont Manrique y de Raúl García Velarde, así como las observaciones y sugerencias que me formularon los dictaminadores anónimos de esta publicación.

${ }^{1}$ La hematoxilina fue un colorante fundamental ampliamente utilizado en la manu- 
Distingo dos modalidades de la piratería registrada en la península de Yucatán: la del saqueo y el asalto; y la forestal o de la extracción del palo de tinte. La del puerto de Campeche corresponde a la primera y la de la Laguna corresponde a la segunda modalidad, cuya característica distintiva es una directa relación con la expansión de la manufactura textil inglesa que requería de la hematoxilina, el mejor de todos los colorantes disponibles. Esa estrecha relación, a su vez, confirió tiempos y sentido lógico a las actividades de dicha ocupación, sin excluir esporádicos acechos y asaltos en el resto de la Península.

La mayor parte de los especialistas utilizan la categoría pirata para referirse a todos los hombres que llevaban a cabo actividades ilícitas y criminales o contra la Corona española (Pérez Martínez 1937; Rubio Mañé 1953; Piña Chan 1977; Bolívar 2000a; Vega Alí 2001; Cantarell 2004; entre otros). Suelen no hacer una separación analítica, a pesar de que rara vez asocian los piratas que asediaron al puerto de Campeche con los que frecuentaban la Laguna. Piratas son todos aquellos que robaban, asaltaban y saqueaban barcos y poblados.

Con base en los trabajos ya citados y de otros estudios del tema -Cruz (1962); Juárez Moreno (1972); de Jármy Chapa (1983); Mota (1984); (Justo Sierra 1998); López Zea (2003); entre otros-, me percato que en la prolongada ocupación pirática de la Laguna (1558-1717), el modus operandi del contingente ahí localizado tuvo cambios. De un mero lugar de refugio se convirtió en un escenario de producción con una estrategia de piratería forestal específica. Unos entraban -variaba el tiempo de la estancia- y otros salían, no hubo colonización.

Además, lo que sabemos de la ocupación pirática de la Laguna que duró alrededor de 150 ańos proviene, en su mayor parte, de

factura textil inglesa. La hematoxilina, pertenece al grupo de los neoflavonoides que se extrae del duramen o parte central del tronco del palo de tinte. La hematoxilina -o hematina- da por ella misma un color azul a morado en función del $\mathrm{pH}$. Su importancia comercial se debía a que contiene una sustancia que al oxidarse se transforma en un colorante: hematina, que era utilizada para la elaboración de tintes de diversos colores una vez agregados distintos fijadores metálicos. 
fuentes primarias: por lo general de archivos de las autoridades y crónicas espańolas. Por tal motivo, considero valiosas las narraciones de William Dampier ${ }^{2}$ que son fundamentales en este ensayo interpretativo. A partir de su obra, Dos viajes a Campeche, por cierto, profusamente citada por Bolívar (2000 y 2000a), señalo varios de los factores económicos que hicieron posible la prolongada ocupación pirata de la región de la Laguna.

El primer gran ciclo de la piratería del siglo XvI se extiende, según López Zea, de 1497 a 1603. Según él, hay dos etapas de alrededor de 50 ańos cada una; la primera dominada por los franceses, de 1500 a 1550; y la segunda por los ingleses de 1550 a 1600 (2003, 12). En este mismo orden de ideas, distingo dos etapas en la ocupación de la Laguna: la de despegue y la del apogeo. La etapa del despegue de la extracción del palo de tinte por los piratas ingleses en la Laguna habría ocurrido entre el último cuarto del siglo Xvi y el primer cuarto del siglo xvir y fue un proceso lento e irregular. ${ }^{3} \mathrm{~A}$ decir verdad, de este periodo sabemos muy poco.

La segunda etapa de apogeo abarcó tres cuartas partes del siglo XVII, finalizando en 1717. Mientras la manufactura textil inglesa crecía, el Caribe resentía la hegemonía de los corsarios ${ }^{4}$ ingleses.

${ }^{2}$ William Dampier (1652-1715) es un explorador y capitán marinero, comenzó a navegar a los 16 ańos. Viajó dos veces a la Isla de Tris entre 1675 y 1678 cuando formó parte de los bucaneros en Jamaica donde había trabajado (1674) como capataz en las plantaciones de caña de azúcar. Este hombre es importante porque es el autor del único documento escrito sobre la actividad de los piratas en La Laguna. Posteriormente se convirtió en el primer Capitán de la marina en circunnavegar el mundo tres veces. La primera en 1679, la segunda 1699-1701 y la tercera 1708-1709. Sus testimonios y observaciones fueron publicadas en Voyages and Descriptions el año 1699.

${ }^{3}$ No debemos pasar por alto que el contingente conocido como piratas del Caribe en sus primeros ańos era gente europea común, por lo general, pescadores o desamparados (Jármy Chapa 1983, 33) que sabían muy poco del comercio de materias primas. En todo caso, a ellos les interesaban el oro y las joyas y no veían cómo de la flora local podría, obtener la riqueza que anhelaban.

${ }^{4}$ Los corsarios compartieron los usos y costumbres de la piratería que ya se iba institucionalizando en América. Sus ataques se extendieron a todos los mares americanos, Pacífico incluido. Estos piratas y corsarios fueron respaldados por sus naciones mediante una patente de corso, también por la burguesía mercantil y por la clase nobiliaria. Los poderosos pusieron dinero y celebraron a estos corsarios que eran vistos como auténticos héroes nacionales. Tenían a su disposición embarcaciones de enorme tonelaje y gran capacidad de fuego, embarcaciones ligeras y de gran maniobrabilidad, con un poder ofen- 
Durante el siglo XVII, el contingente de corsarios -o privateers- familiarizados con la creciente demanda de materias primas, alentada por la manufactura textil, de viviendas, de barcos, etcétera, aumentó de manera considerable. ${ }^{5}$ Sin embargo, el contingente de piratas de la Laguna durante esa etapa de apogeo nunca fue muy nutrido, entre 200 y 400 personas, pues estos aventureros detestaban el trabajo duro e insalubre en los tintales. Además, el negocio del palo de tinte era complejo y no se podía entrar de un día para otro. Se requería la conjunción de varios factores de tipo empresarial que el pirata común carecía.

Por todo lo anterior, en el presente ensayo se subraya que esta piratería registrada en la Laguna constituye una modalidad de la piratería americana, más directamente relacionada con la economíamundo a través de tres factores: 1 . El trabajo organizado tierra adentro para obtener ganancias o dinero; 2 . El proceso de trabajo para transformar el árbol en troncos, en materia prima o si se quiere en valor de cambio; y 3. el factor mercado o intercambio de esa materia prima por dinero o productos industrializados. La presencia de estas actividades ligadas y sometidas a la lógica del capitalismo europeo ilustra uno de los primeros episodios en América Latina de la economía-mundo, que recién se extendía mediante la intervención de los corsarios sumamente beligerantes -también llamados perros del mar-y los privateers, menos beligerantes y con más habilidades empresariales. Ambos ligados al poder de la burguesía emergente.

Según Wallerstein, a finales del siglo xv y principios del xvI con el impulso de la manufactura textil, nació la economía-mundo europea. No era propiamente la red de un imperio, sin embargo, era espaciosa como un imperio y compartía con él algunas características. Es una entidad cuya fortaleza es la acción económica y no la

sivo, gran disciplina a bordo, la consideración a ejercer un comercio libre, que los espańoles consideraron contrabando y una mayor beligerancia anticatólica (Lucena Salmoral 1992, 88).

5 "La ecología mundial se vio alterada, y esto de una forma tal que, debido a la organización social de la emergente economía-mundo europea, beneficiaría primariamente a Europa. Además del alimento, la otra gran necesidad básica era la madera: madera para la leña, madera para la construcción de barcos" (y madera para la construcción de casas y mobiliario para las residencias y edificios públicos) (Wallerstein 1999, 63). 
acción política, al contrario de los imperios. El capitalismo es por su propia lógica interna un sistema necesariamente global, dice el mencionado autor, en su proceso de expansión transforma los espacios y rincones de la vida tradicional (esto es en parte, lo que se quiere ilustrar con el caso de la Laguna).

La economía mundial capitalista, dice Wallerstein, comporta tres elementos básicos: en primer lugar consta -dicho figuradamente- de un solo marco, el cual está regido por el principio de la maximización de los beneficios; el segundo elemento básico es la existencia de una fuerza diferente hacia dentro y hacia fuera; y el tercer elemento esencial de la economía-mundo consiste en que la apropiación del plus del trabajo - desde luego- se da en unas condiciones de explotación, pero las dos clases sociales (burguesía y proletariado) no son su componente fundamental, sino tres fases: espacios centrales (por ejemplo, Inglaterra), semiperiferia (Jamaica y Nueva Inglaterra) y países y regiones periféricas (la Laguna).

En una economía-mundo capitalista, el Estado se convierte no tanto en la empresa económica central -como fue el caso del imperio español-, sino en el medio de asegurar ciertos términos de intercambio y de transacciones económicas (Wallerstein 1999, 22-23). El Estado inglés, en esta época, utilizó su energía política (vía piratas y corsarios) para arrebatar y asegurarse derechos monopolísticos. En la Laguna no tuvo tanto éxito como en Jamaica o Belice. La explotación del palo de tinte continuó poco después de la expulsión pirática, claro está, bajo otro esquema y el control dictado por la Corona española (Contreras Sánchez 1990; Vadillo López 1994, entre otros).

A continuación, el lector encontrará una breve descripción de la región de los tintales, convertida en un escenario de producción; en el siguiente apartado se formula una caracterización de la piratería forestal, destacando tres factores: el trabajo transformador, el intercambio comercial y los agentes intervinientes; posteriormente hago una narración breve de los intentos y de la expulsión definitiva de estos piratas de la Laguna; $y$, antes de formular unas conclusiones parece conveniente una contextualización más amplia de las piraterías en el Caribe y Golfo de México con sus alcances en el contexto americano y europeo. 


\section{LA REGión DEL PALO DE TINTE}

En el año 1565 el gobernador de la provincia escribió: "hay de esto - palo de tinte- tanta cantidad que todas las costas de estas provincias, Yucatán y en la de Tabasco y Nueva España que se pueden cargar cada año todas las carracas ${ }^{6}$ del mundo" (Justo Sierra 1998, 71-72). La región de la Laguna ${ }^{7}$ se encuentra localizada en la porción suroccidental de la península de Yucatán y su eje principal ha sido la Isla del Carmen. Limita al norte con el río Champotón, al sur con los ríos Usumacinta y San Pedro, al occidente con el Golfo de México y al oriente con el espacio boscoso que se extiende hasta la frontera con Guatemala (Vadillo López 1994, 22).

Los historiadores apuntan que la Isla de Términos -también conocida como de Tris y más tarde como Isla del Carmen-, junto con la porción territorial de sus alrededores, tiene una historia singular, ya que los espańoles la descubrieron pero no la conquistaron ni la colonizaron. La isla de Términos aparece registrada en la ruta del descubrimiento, ${ }^{8}$ pero después de esa exploración inicial fueron los piratas el primer contingente de europeos que llegó ahí probablemente a refugiarse y, más tarde, aprovecharse de los recursos naturales de la región (Pérez Martínez 1937; Piña Chan 1977; Justo Sierra 1998, 60; Bolívar 2000).

Inevitablemente grandes porciones territoriales del nuevo continente permanecieron fuera del control colonial español. La colonización del continente recién descubierto, debido quizás al extenso territorio conquistado, fue una tarea que le quedó grande a la Corona española. El reto de las autoridades fue decidir dónde comenzar y hacia dónde extender la colonización. Como bien se sabe, los me-

${ }^{6}$ Nave de casco muy alto, gran capacidad de carga y de andar lento, pero que tenía mucha seguridad durante las tempestades (Cruz 1962, 109).

${ }^{7}$ Esta sería la que Vadillo López llama región del palo de tinte, la cual, por supuesto, ya no existe como tal.

${ }^{8}$ Incluso, "Alonso de Ávila estuvo primero en Acalán, rica provincia comercial cuya capital era Izancanac, situada en la margen del río Candelaria y hoy conocida como el sitio arqueológico El Tigre; [...], la provincia estaba ocupada por mayas-chontales, quienes controlaban el comercio del sur de la península" (Piña Chan 1977, 23-33), pero la organización política de estos moradores era bastante débil. 
tales preciosos y la mano de obra indígena dieron sentido y orientación a dicha colonización. Así, la ausencia de esas fuentes de riqueza es una de las razones por la que la región de la Laguna fue "desdeñada” por los ibéricos.

Es importante destacar que la región de la Laguna (hoy municipio de El Carmen) nació al mundo occidental de cara a la economía-mundo ${ }^{9}$ y no por medio de la colonización española como el resto del territorio del país. ${ }^{10} \mathrm{La}$ Laguna comenzó a ser colonizada poco después del 16 de julio de 1717, cuando los españoles alcanzaron la victoria tras una batalla heroica contra los piratas que intentaban recuperar - por enésima vez- la región a sus dominios. Inmediatamente después de la victoria, comenzó el proceso de incorporación definitiva a la jurisdicción de la Nueva España ${ }^{11}$ mediante la colonización y el impulso de la explotación del palo de tinte (Rubio Mañé 1953; Millet Cámara 1990; Contreras Sánchez 1990; Vadillo López 1994; Cantarell 2004).

La cuenca de la Laguna de Términos tiene forma de una ensenada o albufera, limitada al norte por la Isla del Carmen. La región cuenta con un territorio que abarca un área de $20 \mathrm{mil} \mathrm{km}^{2}$, aproximadamente, y tiene como punto de referencia central la Laguna de Términos donde desembocan varios ríos. Entre los más importan-

${ }^{9}$ Un proceso similar experimentó la zona de Bakalar donde el gobierno colonial español no logró expulsar a los piratas ingleses. Ahí se quedaron y fundaron Honduras Británicas, más tarde con su independencia nació Belice (Calderón Quijano 1944; Gargallo y Santana 1993). La reincorporación de este territorio carmelita al control del gobierno colonial, en efecto, pasó por la urgente reanudación de la explotación del palo de tinte y su comercialización en Europa pero no es menos importante su significado político en la relación España-Inglaterra.

${ }^{10}$ La expulsión definitiva ocurrió en el año de 1717 y mediante la construcción de un "Presidio" - una posición militar española de jerarquía menor a un fuerte (Antochiw 2004) - se inició la colonización. Hoy, a posteriori, vemos que a tiempo fue rescatada y vigilada adecuadamente, antes que corriera la misma suerte que Bakalar, otra porción de la gubernatura colonial de Yucatán, hoy Belice (véase Calderón Quijano 1944; y Gargallo y Santana 1993).

${ }^{11}$ Todavía debieron transcurrir unos años para que "en la región del Presidio, los (nuevos) cortadores habilitaron los canales que los ingleses habían abierto cuando estuvieron establecidos en la Laguna. Por dichos canales conducían chalanas con palo de tinte hasta la rivera donde estaban las embarcaciones mayores para posteriormente transportarlos a los navíos mercantes" (Contreras Sánchez 1990, 47). 
tes: el río Palizada, el río Candelaria y el río Chumpán. La de Términos junto con otras lagunas menores y ríos forman un sistema fluvial complejo conectado tierra adentro con los ríos Usumacinta y Grijalva de Tabasco y hacia el mar con la Sonda de Campeche. De modo que un punto de confluencia natural fue la Isla de Ciudad del Carmen (Sales Gutiérrez 1996; Vadillo López 1994).

El palo de tinte, ni se sembraba ni se cultivaba, es un árbol recio espinoso que llega medir 15 metros de altura y oscila entre 45 y 60 centímetros su corteza. Y un árbol requiere de 25 a 30 ańos para alcanzar su madurez. Para el comercio internacional, lo único que se explotaba del árbol era el corazón de los troncos gruesos de donde se extrae el colorante llamado hematoxilina. Se dice que había árboles de los que se podía obtener de 15 a 20 quintales ${ }^{12}$ del corazón de troncos (Contreras Sánchez 1990, 27-28).

En realidad era un medio ambiente bastante hostil al hombre. Incluso era una región escasamente habitada por indígenas mayachontales. La región estuvo cohabitada por grupos sociales pertenecientes a diversas etnias, pero los "chontales fueron los que más dominaron, en tiempo y espacio". Cuando entraron en contacto con los conquistadores, los indígenas de las comunidades de la Laguna de Términos habían alcanzado ya un muy importante grado de desarrollo social, económico, cultural y político" (Cantarell 2004, 26 y 33), pero lejos del nivel de los mayas del noroeste de la Península de Yucatán donde se asentaron los españoles (Piña Chan 1977). Por todo ello, según Vadillo López, es una región única en el mundo (1994, 22-28).

\section{LA PIRATERÍA FORESTAL}

Las tintóreas en general, el palo de tinte en lo particular, debido a las cualidades químicas de la hematoxilina, alcanzó una alta escala comercial en las últimas décadas del siglo xvi, derivada de la expansión de la industria textil. Los espańoles conocieron esta tintórea porque

${ }^{12}$ De estos árboles habían unos pocos. Si un quintal es igual a 46 kilos, el equivalente sería de 690 a 920 kilos. Tales árboles necesitan un siglo para alcanzar esas dimensiones. 
los mayas desde tiempo atrás la utilizaban para teñir sus mantas. La llevaron a Europa y, científicamente, fue llamada Haematoxylum Campechianum. El robo de este colorante por parte de los ingleses recorrió un proceso de menos a más con base en los dos polos que lo movían: precios al alza por el aumento de la demanda y la situación difícil que sorteaban los piratas del Caribe.

La escasa información sobre las actividades que llevaron a cabo los piratas en la región de la Laguna es explicable si tomamos en cuenta que los protagonistas eran contingentes con espíritu de aventura más que con ánimos de colonizar. En todo caso, sus historias de trabajo en los tintales, seguramente duro, eran narradas a la gente cercana a ellos y pronto quería olvidarlas.

Ya dije antes que, William Dampier en su obra A New Voyage Round the World, publicada en Londres en el año 1703, en su volumen II incluye "Two Voyage to Campeachy", describe las costas, los productos y muchas otras cosas que observó mientras participaba en las actividades del comercio del palo de tinte. Dampier pertenece a una estirpe de hombres muy propia de Inglaterra: marino, viajero, aventurero, pirata, escritor y hombre famoso en su tiempo. El análisis que sigue está basado en las observaciones de este viajero recogidas durante casi tres años que duró su aventura en la Laguna.

\section{Etapa de despegue}

Pero antes de entrar de lleno en la revisión de dicha fuente, que corresponde al periodo del apogeo de la piratería del palo de tinte, protagonizado por piratas y bucaneros ${ }^{13}$ y los corsario-comerciantes, conviene hablar de la etapa de despegue. Pérez Martínez (1937), sostiene que los piratas ocuparon la Isla de Términos desde el 26 de octubre de 1558, apenas dieciséis años después de consumada la conquista de Yucatán en 1542. Cuando la piratería en el Caribe prácticamente estaba en una etapa naciente. Los asaltos a las plazas

${ }^{13}$ Los bucaneros son nativos del Caribe. Era gente del común, o del pueblo, raras veces viajaban a Europa, así que formaban parte de la clientela de estos comerciantes contrabandistas que traían los productos y baratijas que bucaneros y filibusteros compraban para su consumo ordinario. 
americanas comenzaron en la isla de Puerto Rico en 1528. Otra fuente señala que en el año de 1573 el gobernador de la provincia, Diego de Santillán, tenía noticias que en Bakalar -hoy Belice- y en Laguna de Términos se encontraban dos establecimientos de piratas (Bolívar 2000, 32).

Sin embargo, ni Pie de Palos, William Parker, Diego Mulato, Morgan, Mansvelt, Scott o Lorencillo, ni muchos otros famosos piratas lanzaron sus bien conocidos episodios de asalto y saqueo a la ciudad de Campeche desde la Laguna (Pérez Martínez 1937; Juárez Moreno 1972; Piña Chan 1977; Justo Sierra 1998; Cantarell 2004). Lo cual indica que el contingente de la Laguna estaba ahí con otro propósito.

Aunque no sabemos con exactitud desde cuándo, no debió haber pasado mucho tiempo después de que los propios españoles comenzaron a explotarlo en el área circundante de la ciudad de Campeche para venderlo a Inglaterra ya que la industria textil española se encontraba en pańales (Vadillo López 1994). La piratería americana, como ya se dijo, es un hecho social complejo cuyas dimensiones económicas, políticas y culturales siguen dando pie a nuevas interpretaciones (Contreras Sánchez 1987; Lucena 1992; Apestegui 2000; López Zea 2003). "El oro y la plata fueron las riquezas que despertaron la mayor ambición, pero también el palo de tinte, ya que la industria inglesa, en lo relativo a la manufactura textil, dependía de los colorantes naturales que únicamente se producían en las tierras tropicales" (Justo Sierra 1998, 40).

En efecto, los estudiosos del tema han afirmado que es la explotación forestal lo que explica la prolongada presencia de la piratería en la Laguna. "En lugar de adquirir esa materia (prima) por el camino comercial con España, [los ingleses] prefirieron abastecerse de ella por su particular iniciativa; todo ello implicó años de ejercicio de la práctica pirata” en la Laguna (Justo Sierra 1998, 40).

Una hipótesis explicativa es que la hegemonía de los corsarios ingleses permitió que los comerciantes ingleses incursionaran con más facilidad en el Caribe y el Golfo de México (López Zea 2003). En 1545 se descubrieron grandes yacimientos de plata en la región del Potosí (Bolivia) y más tarde se encontró plata también en Zaca- 
tecas y Guanajuato (México). Y si bien dicha plata se convirtió en un botín al alcance solamente de los corsarios, ${ }^{14}$ la minería inyectaba energía económica a las poblaciones costeras. De modo que con la llegada de la década de los sesenta (1560) se abre una nueva etapa en la que el contrabando ${ }^{15}$ alcanza dimensiones epidémicas (Apestegui 2000, 45), y aparecen los privateers que llamo corsariocomerciantes.

En el año 1561 comenzó el reino de España a organizar dos flotas: una para el virreinato de la Nueva España y otra para el Perú. Dichas flotas constaban de un gran número de mercantes y una custodia de buques de guerra (Cruz 1962). Las flotas tenían algunos puertos fijos de recalada que se convirtieron en el objetivo favorito de piratas, por ejemplo, Cartagena, Portobelo y Veracruz. Tras la victoria sobre la armada invencible (1588), los ingleses se convirtieron en dueños y señores del océano Atlántico. Según Lucena Salmoral, los 52 ańos transcurridos entre 1569 y 1621 marcaron el apogeo de la piratería apoyada por las coronas europeas -o sea de los corsarios- $(1992,87)$.

A su vez, otros navegantes, comerciantes ingleses independientes aliados con piratas, pero no propiamente lo eran, se lanzaron a la aventura. ${ }^{16}$ Un ejemplo de ellos es John Garret, mercader de Plymouth y amigo del famoso corsario Francis Drake. Transportaba mercancía a los puertos del Canal de la Mancha y del Mar del Norte.

${ }^{14}$ Es importante precisar que por corsario se entiende el robador en el mar de carácter privado que cuenta con el permiso de su gobierno para saquear naos mercantes enemigas; mientras que por piratas se entiende el robador en el mar, privado y criminal que no cuenta con permiso ni licencia de ningún gobierno (López Zea 2003, 11-12), ni mucho menos con los pertrechos militares de aquéllos.

${ }^{15}$ Desde el siglo xvı, debido al derecho monopólico que se arrogó la Corona española, el tráfico ilegal a espalda de las autoridades coloniales, era una práctica común en algunas regiones de ultramar. Dado el insuficiente desarrollo manufacturero español, los tejidos, artículos de uso doméstico, herramientas, bebidas alcohólicas, aceite, etcétera, provenían del contrabando. A cambio, los contrabandistas llevaban a sus metrópolis fundamentalmente materias primas: frutos de la tierra, azúcar, tabaco, algodón, cacao, maderas tintóreas y preciosas.

${ }^{16}$ Frecuentemente, los contrabandistas, cuando las fuerzas de guarnición de los pequeńos puertos de las costas americanas no eran suficientes para su completa defensa, cometieron depredaciones y asaltos llevándose por la fuerza lo que se les negaba por el trueque (Pérez Martínez 1937, 9). 
Se enriqueció gracias a que se convirtió en un audaz mercader contrabandista y pirata (López Zea 2004, 123). Algunos de estos llamados también "Merchant adventurers" solían transportar de regreso a Inglaterra el palo de tinte. Eran traficantes de mercancías y de materias primas, que en la literatura local se les nombra como "compradores" y/o "contrabandistas". ${ }^{17}$

Durante el segundo cuarto del siglo XVII (1622-1655) la piratería adquirió perfiles propios, ${ }^{18}$ despegándose de su tutela europea. Inglaterra se concentró en la colonización de Norteamérica y en sus problemas internos suscitados por el parlamentarismo y la monarquía. Francia canalizó sus fuerzas para la gran batalla contra los Habsburgo en Europa. Sólo Holanda siguió prestando respaldo oficial a sus corsarios. En tales circunstancias la piratería americana cobró la modalidad del bucanerismo y filibusterismo. ${ }^{19}$ Entre 1671 y 1722 se vive la etapa del filibusterismo (Lucena Salomoral 1992).

${ }^{17} \mathrm{El}$ negocio del contrabando fue iniciado por los marinos portugueses y bien pronto las aguas antillanas se vieron pobladas de embarcaciones extranjeras (Pérez Martínez 1937, 9).

${ }^{18}$ La verdadera piratería americana, la auténticamente indiana, apareció a fines del primer cuarto del siglo XviI. Los bucaneros era gente sin rey procedente de cualquier nación y establecidos en el Caribe, el corazón de América española. Nadie sabe cómo nacieron los bucaneros, pero aparecieron en la zona norte y sobre todo en la noroccidental de la isla Espańola (Santo Domingo). Los bucaneros fueron cazadores de reses o puercos cimarrones y preparadores cocineros de su carne, que vendían luego a las tripulaciones de los barcos piratas y corsarios. Sus cacerías en el monte duraban como mínimo seis meses, a veces hasta dos años. Con el dinero obtenido de la venta de carne y pieles compraban los útiles necesarios: armas, pólvora, telas, etcétera. Una parte del mismo lo invertían invariablemente en sus grandes placeres, es decir, el alcohol, el tabaco, el juego y las mujeres. Aunque el bucanero era el cazador de ganado salvaje, pronto se vio en la necesidad de piratear, entrando a formar parte de los aventureros del mar. El creador del nuevo género parece que fue Pedro el Grande (Pierre Le Grand). Muchos bucaneros se dedicaron a piratear, abandonando su vida pacífica de cazadores, así en menos de dos años surgieron más de veinte navíos bucaneros (Lucena Salmoral 1992, 150-155).

${ }^{19}$ Los filibusteros nacen de la fusión de los bucaneros de la Isla Tortuga con los piratas y formaron la ralea más temible de malditos del mar en el siglo xvir. Los filibusteros nacieron de los bucaneros cuando éstos abrazaron abiertamente la piratería. Los españoles contribuyeron a ello al exterminar el ganado cimarrón que había en Santo Domingo, que era lo que cazaban los bucaneros. Después de 1620, fueron expulsados los bucaneros de Isla Tortuga por los españoles. En 1640, esta vez como filibusteros, volvieron a dicha isla donde permanecieron hasta 1653. La Tortuga fue la Meca del filibusterismo (Lucerna Salmoral 1992, 156-158). 
El comercio español con el palo de tinte de Campeche a Sevilla creció de manera importante en la última década del siglo xvi. Entre 1590 y 1600 el promedio de barcos que hacían esa ruta creció a un promedio de tres por ańo, cuando en la década anterior el promedio registrado había sido de uno por año (García Bernal 2006, 64, 65, 93,95 y 149). La autora documenta muy bien que la carga principal de esos barcos eran: el palo de tinte, de 200 a 4,000 mil quintales por ańo; y cueros, de 150 a 1500 quintales por año. ${ }^{20}$ García Bernal considera que en estos años finales del siglo XvI, los navíos comerciales españoles se vieron atraídos por la oferta de productos tintóreos de la región (Bernal 2006, 93).

Según Bolívar, Juan de Dios Bonilla en su libro Apuntes para la historia de la Marina Nacional, informa que en 1597 "ya existía un grupo de piratas ingleses establecidos en esta región" (Bolívar 2000a, 32 , subrayado mío), o sea, de tiempo atrás, haciendo trabajos de talar, acarrear y astillar los troncos de manera organizada. Además, ya para entonces la hematoxilina demostraba que era una de las mejores tintóreas del mundo. No es raro entonces que las primeras extracciones del palo de tinte en la región de la Laguna, por los ingleses, hayan iniciado en el último tercio del siglo xvı.

\section{La etapa de ange}

La etapa de auge en la Laguna comienza en el segundo tercio del siglo xvir. Hay un párrafo en la obra de Dampier que nos hace pensar que la piratería y tráfico del palo de tinte era practicado por los corsario-comerciantes desde antes que Jamaica (1655) se convirtiera en una base inglesa.

Después de que los ingleses tomaron Jamaica y -los bucaneros- comenzaron a circundar esta bahía, encontraron muchas barcas cargadas con él

${ }^{20}$ Este es otro tema, pero quiero citar una frase de Dampier que me parece relacionada con este producto yucateco de exportación "Si no hubiera sido por el gran cuidado de los españoles en surtir las Indias Occidentales con cerdos y reses -que pastaban libremente entre los otros animales salvajes- los piratas hubieran muerto de hambre" (2004, 229). 
-palo de tinte-, pero al no conocer entonces su valor, lo abandonaban a la deriva o lo quemaban salvando sólo el trabajo de acero y los esclavos, algo que ahora es usual entre los piratas, sin percatarse de alguna manera del cargamento, hasta que el capitán James, tras haber tomado un gran barco cargado de éste y habiéndolo traído a Inglaterra para proveer a un pirata, más allá de sus expectativas vendió la madera a un precio muy alto (Dampier 2004, 127).

Este hecho narrado, confirma que muy pocos piratas conocían el valor de este colorante en el mercado europeo. Evidentemente, no fueron los piratas comunes los que descubrieron el palo de tinte en la Laguna. Sin embargo, este contingente aportaba la mano de obra para el negocio en manos de los corsario-comerciantes. Hay reportes de las autoridades españolas señalando que los barcos sin bandera cruzaban la bahía de Campeche con palo de tinte desde mucho antes que Jamaica fuera anexada formalmente al imperio británico. Por ejemplo, en el año 1632, fueron divisadas seis urcas frente a la boca de la Bahía de Campeche pero no atacaron al puerto (Mota 1984, 292). "En julio de 1678 el corsario inglés Cook estuvo merodeando por las costas de Campeche, pero todo se redujo a cargar sus barcos con leños de palo de tinte y no dejó huellas de sangre" (Juárez Moreno 1972, 55).

En la geopolítica del siglo XVII, Jamaica es una pieza clave. Si bien desde finales del siglo anterior era asediada y a veces tomada por los agentes de la reina Elizabeth I, en el año 1655 esta isla oficialmente pasó a formar parte de Inglaterra. Jamaica se convirtió en la base más importante de abasto y diversión de bucaneros y filibusteros. A su vez, desde ahí se controló el tráfico en la cuenca del Caribe de productos y materias provenientes de y hacia los puertos ingleses. En palabras de Dampier: "Este comercio tuvo su auge tras la decadencia de la piratería ya que después de que Jamaica quedó bien fundada por los ingleses y se estableció la paz con España -en 1671-” (2004, 139), los piratas tuvieron que componérselas por sí solos en actividades consideradas no criminales.

El negocio del palo de tinte ocasionó cierta depredación del medio ambiente. Cabo Catoche fue uno de los primeros sitios de la 
Península donde los bucaneros se vincularon con el negocio del palo de tinte que lo explotaron sin medida, a tal punto que cuando él hacía su primer viaje a la Laguna en 1675, la región ya estaba abandonada: "antiguamente lo frecuentaban mucho más los hombres de Jamaica, quienes venían hasta aquí en balandras para cargarlas de ellos, hasta que todos los árboles de palo de tinte cerca del mar fueron cortados; ahora está abandonado por completo, ya que acarrearlos hasta la orilla exige más trabajo que talar, cortar y astillar" (Dampier 2004, 53). Obviamente, cuando la extracción de árboles en una región requería más esfuerzo que en otra región ya conocida, sencillamente era abandonada.

Con esta breve contextualización del prolongado proceso histórico de la piratería en la Laguna podemos darnos cuenta de la compleja articulación de estas actividades ilícitas con los grandes intereses de las potencias europeas y de sus agentes. La multicitada presencia de unos asentamientos humanos en la región varió a lo largo del periodo y, en el siglo XVII, eran en realidad campamentos de un contingente cambiante y jerarquizado. Asentados cerca de los tintales y no en la Isla de Términos. Así que conviene abundar un poco más sobre su modus operandi en la etapa de auge.

\section{La organización productiva en la Laguna}

William Dampier (2004) es uno de esos personajes que hacían el vínculo entre bucaneros y corsario-comerciantes. Dampier comenzó a navegar a los 16 años y se convirtió en el primer capitán de la marina inglesa en circunnavegar el mundo tres veces. Es un aventurero a la vez que un visionario en los negocios, no representa ni al corsario ni al pirata común. Si bien no recibió educación formal como otros viajeros al estilo de Humboldt o de Stephens, sus observaciones son el único registro disponible de las actividades que llevaron a cabo los hombres de la Laguna.

Si no sabemos cuando comenzaron tampoco tenemos idea de cuánto palo de tinte se llevaron mediante la intervención de bucaneros y corsario-comerciantes. Victoria Ojeda afirma que las autoridades españolas calculaban una cantidad de 120 quintales al año 
(2003, 100), la cual arroja una cantidad $(120 \times 46)$ de 5,520 kilos, o sea de 6 toneles, que por todo lo que ya dijimos parece una estimación muy corta.

Por ejemplo, Dampier cuenta que colaboró con un grupo de cortadores, casualmente en los mismos años de la fuente que cita Victoria Ojeda: "Eran una compañía de seis, quienes tenían 100 toneles ya cortados en troncos y astillados, pero no lo habían acarreado del lado de la ensenada y esperaban un barco de Nueva Inglaterra que llegaría en un mes o dos para llevárselo" (2004, 197-199). Si un grupo de 6 hombres cortaba 100 toneles, pongamos en un año, y si había 260 taladores, divididos en 43 grupos, entonces, conservadoramente, cortaban unos 4,000 toneles al año. Un tonel inglés antiguo equivalía a 20 quintales. Por lo tanto, se cortaban alrededor de 80,000 quintales. O sea, 40 embarques de 100 toneles cada uno.

En realidad no importa demasiado la precisión de cuánto, pero si es necesario dejar claro que no eran pequeńas cantidades. Era un negocio que había alcanzado una escala considerable. Con el paso del tiempo la Laguna se había convertido en un territorio estratégico para la industria textil inglesa cuyos productos (telas, paños y ropa), a su vez, eran distribuidos en el nuevo contexto mundial. La Laguna, si alguna vez lo fue, de ser un simple refugio contra las adversidades del mal tiempo se convirtió en una tierra con potencial de hacer dinero. De esto se empapó muy bien Dampier antes de escoger la Laguna entre otras opciones (Dampier 2004, 49).

Pero es dudoso que "En la Isla de Tris los piratas llegaron a contar con una estación naval, suficientes hombres y buques desde donde preparaban los asaltos con los principales puertos del Atlántico" (Sosa 1984, 36). Evidentemente, jamás hubo aquí instalaciones de algún tipo semejantes a una estación naval. Durante la etapa de auge más bien hubo campamentos organizados con la clara finalidad de optimizar el esfuerzo individual para obtener dinero (o productos) por el trabajo realizado y también hubo tráfico de barcos de diferentes tamańos y calados dedicados al transporte de la materia prima.

A mediados del siglo XvII, el negocio del palo de tinte se encontraba en su apogeo. Los bucaneros ya habían establecido una estre- 
cha relación comercial con los corsario-comerciantes. ${ }^{21}$ Eran parte del mismo negocio, pero cada uno con plena libertad. Dampier mismo hace una distinción entre bucaneros y corsarios: "desde que los corsarios y los barcos de palo de tinte navegan por esta ruta, estos pescadores - de la costa de Yucatán- son muy silenciosos" para evitar ser asaltados.

Desde una perspectiva teórica, las actividades desplegadas por los piratas en la Laguna caen en la categoría producción mercantil. La producción mercantil es una interacción del hombre y la naturaleza organizada mediante un mecanismo autorregulador de trueque y cambio. O sea, sujeta a la oferta y a la demanda. "El comercio del palo de tinte se había vuelto muy común antes de que yo llegara a aquel lugar; había aquí [...] como 260 o 270 hombres que vivían todos en la laguna y en la Isla de la Carne" -hoy Atasta-(Dampier 2004).

\section{Los taladores}

La explotación del palo de tinte estableció una cadena de intercambio comercial entre bucaneros convertidos en trabajadores del bosque y los privateers. Gracias a lo cual el bosque de árboles de tinto (los tintales) si bien no tenía un valor por sí mismo, nadie era propietario de la tierra, se transformó en fuente de valor a partir de la demanda generada a miles de kilómetros de ese lugar. Estos tintales se transformaron en un medio que valorizaba la fuerza de trabajo. La relación empresario-obrero estaba ausente, era puramente mercantil. O sea, la fuerza de trabajo no se vendía sino que se objetificaba en unos trozos del palo de tinte y luego se intercambiaba por dinero o productos.

Usualmente, la actividad productiva en los bosques o en las minas da pie a una división del trabajo y a unas relaciones de producción más amplias. Por ejemplo, a la relación propietario-trabajador y de ahí a un asentamiento humano alrededor de la explotación de

21 "Los compradores, algunos venían de Londres o Jamaica, también de las posesiones inglesas en Norte América, especialmente de Nueva Inglaterra y Nueva Escocia” (Bolívar 2000, 33). 
los recursos naturales. En esta región no ocurrió así, debido a que los bucaneros siempre corrían el riesgo de ser desalojados. El de los tintales era un trabajo duro e ilegal, con el consecuente riesgo de caer prisionero de las autoridades españolas. Para todos los efectos de sobrevivencia, levantaban campamentos cerca de su negocio y los contratos eran verbales.

El palo de tinte crece en forma silvestre por lo tanto no se requiere de inversión alguna para su explotación. Este negocio (talar, acarrear, desastillar y cortar árboles de palo de tinte) sólo requería de una infraestructura mínima. La madera una vez talada era acarreada hacia los ríos y procesada para venderla como materia prima. El proceso consistía en talar el árbol; trasladar los troncos al agua de los ríos para concentrarlos en un sitio donde se desastillaban; el corazón del tronco, la parte realmente útil, era entonces cortada en piezas de un metro de largo aproximadamente. Así procesados eran finalmente transportados al barco grande anclado en la barra de la isla.

A los taladores se les pagaba en especie (licor, telas y productos indispensables para la sobrevivencia) y en menor medida con billetes. "Pero si cualquier hombre viene a comprar-palo de tinte-con billetes pagaderos en Jamaica, puede estar seguro que le darán la mejor madera" (Dampier 2004, 195). A diferencia de las ganancias que obtenían por el saqueo, la participación en la actividad del palo de tinte permitía a los bucaneros una ganancia directamente proporcional con el trabajo realizado en la cadena del comercio o tráfico del producto.

Como se deduce de lo anterior, el dinero y la ganancia son categorías que manejan a la hora de tomar decisiones. Dampier antes de hacer su primer viaje a la Laguna ponderó muy bien sus oportunidades y los riesgos, por ello abandonó el empleo más seguro pero mal pagado que tenía en las plantaciones de caña de azúcar en Jamaica. Hizo un primer viaje al golfo de Campeche en 1675 que le permitió confirmar sus expectativas de mejorar sus ingresos en el negocio del palo de tinte: "Después de 6 o 7 meses (en las plantaciones de caña de azúcar), dejé también aquel empleo y me embarqué a bordo del Capitán Hudsel, que se dirigía al golfo de Campeche, a cargar-comprar-palo de tinte" (Dampier 2004, 51). El barco zar- 
pó de Puerto Príncipe a comienzos de agosto de 1675 y llegaron a isla Tris en el golfo de Campeche tras 14 días de travesía. ${ }^{22}$

Dampier vivió en la región cerca de tres años, "ya que vi grandes oportunidades de hacer dinero ahî" (Dampier 2004, 71).

Ahora el capitán Johnson de Nueva Inglaterra partía de nuevo hacia el golfo de Campeche y yo aproveché la oportunidad de ir como pasajero con él, resuelto como estaba a pasar un tiempo en el comercio de palo de tinte. [...] En poco tiempo me establecí en la ensenada oeste de la laguna Oeste con unos antiguos taladores de palo de tinte (Dampier 2004, 115).

Los mencionados taladores eran bucaneros asentados en la región pero no propiamente colonos. Cada campamento tenía su gente y predominaba entre ellos el trueque y el compromiso de la palabra.

Los ríos y lagunas formaban un sistema fluvial que facilitó a los ingleses se adentraran en la zona a talar palos de tinte muchos kilómetros tierra adentro en la zona. Algunos de los taladores de la Laguna era gente experta, especializada en el transporte, que conocía los arroyos y ríos que formaban un sistema fluvial amplio. Los taladores formaban pequeños grupos ( 3 a 10 personas) muy bien organizados. "Los cortadores de palo de tinte son por lo general hombres fuertes y robustos, y cargarán pesos de 300 a 400 pesas, pero se deja a la elección de cada hombre cargar lo que le place". "Algunos tumban árboles, otros cortan con la sierra en troncos convenientes y por lo común quien astilla la savia es el principal" (Dampier 2004, 193).

Nuestro cronista no detalla el pago exacto por cada tarea realizada después que el árbol ha sido talado. Lógicamente había una distribución del trabajo entre los hombres de la Laguna, algunos hacían un trabajo especializado. Por ejemplo, cada "pequeña compañía" tenía un líder que pagaba cinco libras por tonel de madera talado. El transporte de los troncos procesados se hacía por medio

${ }^{22}$ El regreso fue increíblemente largo y accidentado. A causa del mal tiempo les llevó cerca de dos meses para alcanzar nuevamente Jamaica. "No pasó mucho tiempo después de nuestra llegada a Port Royal, antes de que se nos pagara y se nos diera licencia” (Dampier 2004, 115). 
de unas canoas propias para la navegación fluvial llamadas piraguas. El hombre que conducía la piragua era al mismo tiempo el dueño y cobraba por sus servicios, no dice el autor cuánto.

Algunas veces contactaban a los nativos, pero no era común el contacto cercano entre ellos. Se ha dicho que, "Los ingleses tenían ya tal dominio sobre la Laguna de Términos que poseían jornaleros mayas para el corte de palo de tinte que transportaban en navios de alto bordo a las colonias de Nueva Inglaterra" (Piña Chan 1977, 70, subrayado mío). En realidad, los "jornaleros" no eran los indígenas mayas. Los bucaneros frecuentemente atrapaban a los indios con el objeto de forzarlos a trabajar para ellos pero era difícil retenerlos, escapaban fácilmente. Así que mejor ofrecían productos a cambio del trabajo. Se practicaba el trueque de trabajo-productos ya que el dinero inglés no servía en la Laguna para nada. Es posible que los indígenas ayudaran a transportar los troncos a la ribera de los ríos, de donde luego eran transportados por medio del arrastre o de las chalanas hasta un lugar de recepción llamado "Palotada", población hoy conocida como Palizada.

Los bucaneros alternaban el tipo de trabajo: unos eran taladores y otros eran marineros quienes en la Laguna tenían la tarea -que duraba varios días- de cargar el corazón de la planta al barco que los contrataba. Dice Dampier que visitó tres veces las cabañas de otros taladores y siempre fue bien agasajado con carne de res, de puerco y bollos de masa. La carne era obtenida por medio de la caza en las sabanas. De primera mano supo que esa gente estaba ahí no por voluntad sino forzados por la situación que prevalecía en el Caribe. La piratería, digamos típica, había dejado de ser un buen negocio y ya no era tolerada por los ingleses, así que el riesgo de caer prisioneros era muy alto.

La de los bucaneros era una vida de marino (Cruz 1962, 95113), y la disciplina de una tripulación marina aprendida ayudaba a formar "pequeñas compañías" de 3 a 10 hombres en la Laguna. Para ellos la Laguna era una extensión del mar, no manejaban la noción de territorio. "Si bien podían trabajar lo suficiente si lo deseaban, pensaban que era un negocio pesado aquel de afanarse en cortar madera. Eran buenos tiradores y así tomaban más placer en la 
caza, pero ninguno de aquellos empleos les impresionaba tanto como la piratería" (Dampier 2004, 137).

No obstante su organización laboral, en el fondo los taladores seguían siendo piratas de corazón, lejos de una mentalidad empresarial. Dampier, como agudo observador que era, reconoció que sus compañeros no olvidaban sus antiguas juergas y solían gastar " $30 \mathrm{o}$ 40 libras en sentarse - a tomar ron tres o cuatro días seguidos- a bordo de los barcos que venían de Jamaica". "Es muy cierto que los taladores de palo de tinte que se encontraban en la bahía cuando yo estaba ahí eran todos enviados o desarraigados, algo que yo temí, y ésa fue la razón que movió por fin a marcharme, aunque era un lugar donde un hombre podía haber obtenido una propiedad" (Dampier 2004, 139, 141, 143).

\section{Corsario-comerciantes}

Piratas, corsarios, bucaneros y contrabandistas estaban en el mismo bando. Sin embargo, cada uno en su empresa. Obedeciendo una razón práctica: los barcos bucaneros no tenían bodegas adecuadas -navíos de alto bordo- para el transporte de materias primas a grandes distancias. El ámbito de los bucaneros era el mar Caribe y Golfo de México. En cambio los corsario-comerciantes surcaban todos los mares y usaban barcos de gran tonelaje, apropiados para los viajes trasatlánticos (Cruz 1962). El negocio de ellos era de dos vías: vender productos industrializados y comprar materias primas y objetos exóticos, para luego venderlos en sus puertos de origen.

Una vez que los ingleses se apoderaron de Jamaica en 1655 se registran dos tramos de este comercio de materias primas. El tramo de Jamaica a la Laguna y el tramo de Jamaica a Inglaterra o a las colonias de esta nación en América, como Nueva Inglaterra. La tajada más grande del negocio en el tramo la Laguna-Jamaica se la llevaban los dueńos del transporte o sea los bucaneros propietarios de barcos equipados y hasta armados.

El negocio de los capitanes de barcos bucaneros consistía en contratar taladores y traer el palo de tinte a Jamaica para venderlo a los corsario-comerciantes. El tipo de barco utilizado por los capi- 
tanes bucaneros era el mismo utilizado para los asaltos, mediano, de menor capacidad al que utilizaban los corsario-comerciantes por todo el mundo, que eran las carracas o las urcas. Los capitanes bucaneros eran dueños de barcos medianos y ligeros, principalmente queches o pataches y conocían muy bien el trayecto Jamaica-la Laguna. La duración del viaje dependía de las propias condiciones de navegación y de las maniobras para burlar la vigilancia española.

Los propietarios del transporte eran los dueños del capital, fuera el transporte marítimo o en la propia región de estudio. En el ámbito de la Laguna, había “capitalistas" menores que eran los propietarios de los barcos pequeños y de poco calado para transportar los troncos hacia los centros de acopio. El sistema fluvial de la Laguna, cuyos humedales permitían la abundancia del árbol del palo de tinte a la vez facilitaba el transporte de los troncos del árbol desde muy diferentes distancias tierra adentro.

Los barcos medianos como los queches y los pataches anclaban en la isla de Tris y "los navíos más pequeños -falúas y balandras- de poca calada corren tres leguas más lejos, cruzando sobre una gran laguna que va desde tierra firme" (Dampier 2004, 67). Los compradores debían llegar a Cayo Un Arbusto, al centro de acopio, -lugar que los españoles más tarde llamaron "palotada"- para meter la carga en sus balandras y luego transbordarla al patache.

El barco proveniente de Jamaica traía taladores, productos y dinero, con lo cual se estimulaba el proceso de trueque con los taladores de la Laguna:

Nuestro cargamento para comprar palo de tinte consistía en ron y azúcar, artículos muy buenos para los taladores de palo tinte, que eran entonces alrededor de 250 hombres, en su mayoría ingleses, quienes se habían establecido en varios lugares de los alrededores. [...] no pasó mucho tiempo antes que tuviésemos a estos comerciantes a bordo visitándonos, $[\ldots]$ además del ron que vendimos por galón o barril pequeño, lo vendimos hecho en ponche, [...] no tomamos dinero por él, no esperamos ninguno, ya que el palo de tinte era lo que habíamos ido hasta ahí a buscar y eso obtuvimos a cambio de nuestros artículos (Dampier 2004, 69). 
Había un intercambio de fuerza de trabajo y productos muy ad hoc, pero ordenado. Evidentemente, el negocio con la tintórea atrajo a verdaderos hombres comerciantes radicados en las nuevas colonias inglesas. En el año 1704 una expedición al mando del capitán Francisco Fernández, apresó un centenar de forajidos ingleses y destruyó instalaciones y embarcaciones. Detuvo a 100 ingleses y nueve negros, se apoderó de una urca pequeńa cargada de palo de tinte, un patache de construcción británica con 800 quintales de dicho palo de Campeche, un bergantín español robado y otro construido en San Román (Campeche); también se apoderaron los victoriosos expedicionarios de una balandra, medio centenar de canoas, útiles para diferentes desplazamientos; y por supuesto, miles de quintales de palo ya cortado y listo para embarcarse (Justo Sierra 1998, 62),

Entre los prisioneros se encontraba Isaac Hamilton, judío londinense cuya misión era embarcar el tinte con destino a Nueva Inglaterra; Guillermo Haven, natural de Jamaica y John Eliot, londinense enlistado en Jamaica en la lista de la piratería (Justo Sierra 1998, 63).

Todo lo anterior, deja claro que tanto bucaneros como corsariocomerciantes se movían y actuaban siguiendo la lógica del capitalismo, pero no había obreros, los bucaneros trabajaban por cuenta propia en la lógica del riesgo contra una ganancia mercantil. De la obra de Dampier se desprende que la extracción del palo de tinte se hacía bajo un esquema jerárquico donde la cadena mercantil arrancaba del ámbito territorial de la manufactura, donde era entregada la materia prima. Los dueños de un barco de alto bordo no sólo transportaban palo de tinte; le seguían en esta misma cadena mercantil otros capitanes de barcos menores, incluidos los más menores de la Laguna.

De acuerdo con Wallerstein, se diría que dicha lógica de acción y trabajo del contingente dentro de la cadena mercantil, es un indicador de la expansión de las operaciones reguladas por el capitalismo emergente pero sin caer en la relación típica del capitalismo desarrollado que es la compra de fuerza de trabajo mediante el dinero y del empresario-asalariado. La creciente industria textil, la primera industria importante del desarrollo industrial europeo, era algo más 
que un comercio de lujo -telas y trajes de casimir-era también un aparato hambriento de productos naturales: tintes para los tejidos de algodón y lana y goma para endurecer la seda en el proceso de acabado, etcétera. Era la energía del mercado abriéndose paso por todo el mundo civilizado.

\section{LA EXPULSIÓN DEFINITIVA DE LOS PIRATAS DE LA LAGUNA}

Según el historiador yucateco Molina Solís, “en los años 1559 y 1560 vinieron a la costa de Yucatán y al puerto de Campeche, en diferentes tiempos, dos navíos y en ellos gente francesa, corsarios luteranos" (citado por Pérez Martínez 1937, 18). Pero la temeridad por los piratas cundió entre la población cuando asaltaron y quemaron el puerto de San Francisco de Campeche en agosto de 1561 (Sosa 1984, 35). Otro ataque violento a la Villa fue perpetrado por Parker en septiembre de 1597 (Juárez Moreno 1972, 7-12).

En la década final del siglo Xvi, había entre las autoridades coloniales dos focos de preocupación pero el que más atención recibió fue el puerto de Campeche. No hay que olvidar que la gubernatura (que abarcaba toda la península) de Yucatán era de las más pobres y remotas de la Nueva Espańa. Durante casi tres siglos Yucatán permaneció prácticamente aislado del resto de la Nueva Espańa, ya que el comercio y el transporte se hacían por mar, dos barcos por año, principalmente desde Campeche y Sisal hacia Sevilla (García Bernal 2006). De hecho, sus fronteras hacia el sur, las montañas de Belice y Guatemala (Bracamonte y Sosa 2001) y los pantanos de Tabasco, constituían una cortina que la aislaba del resto de la Nueva España.

Debido a tal condición geopolítica de aislamiento, y porque una defensa militar significaba un gasto fuerte, los gobernadores de $\mathrm{Yu}$ catán no recibieron el debido apoyo que solicitaban. Esto sin soslayar que las autoridades coloniales hicieron varios esfuerzos para expulsar a los piratas de ese enclave. Conseguían el objetivo, pero como no había impedimento tiempo después regresaban. Pasaron muchas décadas para que la Corona comprendiera que la expulsión definitiva de los piratas de la Laguna requería más que nada de una estrategia de colonización. 
Tras numerosos asaltos a la villa de Campeche, en el año de 1629 el rey Felipe IV de España ordenó se creara la Armada de Barlovento para proteger al Golfo de México de la piratería. Sin embargo, la falta de recursos económicos impidió que el proyecto se llevara a la práctica, lo que pudo hacerse varios años después en 1642 (Rubio Mañé 1953). La flamante Armada de Barlovento con base en el puerto de Veracruz fue incapaz de impedir la ocupación de Jamaica que se llevó a cabo en 1629 (Mota 1984, 292) y fracasó en la tarea de expulsar a los piratas de la Laguna.

Pérez Martínez (1937); Rubio Mañé (1953); y Piña Chan (1997, 70), entre otros historiadores, dan cuenta de muchos intentos que fracasaron, como el siguiente: "En 1675 se enviaron de México 900 hombres a Campeche para destinarlos contra la Laguna de Términos". Obviamente, estos hombres venían con una flota, artillería y municiones, pero desconocían el terreno y la capacidad evasiva de estos piratas de la Laguna, en consecuencia fracasaban o, sencillamente, los piratas hacían una retirada estratégica y luego regresaban.

Con más voluntad política que sus antecesores, el rey de España Felipe V, en su primera etapa de gobierno, ordenó al virrey don Francisco Fernández de la Cueva Enríquez que expulsara definitivamente a los piratas de la Isla y se colonizara mediante el establecimiento de un cuartel militar, una fortaleza menor, conocida como presidio. La expedición de 1704 tuvo éxito y logró hacer prisionero a un número indeterminado de bucaneros y capturó grandes cargamentos de palo de tinte, cańones y municiones. Posteriormente, la Isla fue abandonada por falta de recursos para colonizarla y los piratas regresaron, por enésima ocasión, a posesionarse de ella (Rubio Mañé 1953).

La que sería la última expedición se llevó a cabo en el año de 1716 bajo el liderazgo del sargento mayor de Veracruz, don Alonso Felipe de Andrade. En esta ocasión, como en las anteriores, "capturaron embarcaciones de construcción inglesa, cańones, municiones, alimentos y grandes cantidades de maderas preciosas que estaban almacenadas en espera de ser vendidas al exterior; también fueron liberados hombres y mujeres indígenas, así como también 
niños que servían como esclavos a los piratas" (Sosa 1984, 42). Se ordenó la inmediata construcción de una "guarnición presidial", o sea, un fuerte de estacas o recinto cuadrado con cuatro baluartes en los ángulos.

Poco tiempo después, mientras se ocupaban de levantar las defensas, los piratas regresaron fuertemente armados y con apoyo de navíos de guerra. Se presentaron frente a la Isla el 15 de julio de 1717. Tras una feroz batalla, "Cuando el sol del dieciséis de julio de mil setecientos diecisiete alumbró la Isla, la victoria de los defensores de ésta era definitiva [y] al hacer una búsqueda de don Alonso Felipe de Andrade éste fue encontrado muerto en el camino a la playa, hasta donde llegó cuando perseguía a los filibusteros" (Sosa 1984, 44). Y, como el 16 de julio es día de Nuestra Señora del Carmen, todos pensaron que la victoria sobre los piratas había sido un verdadero milagro atribuido a dicha virgen. De ahí adelante la isla recibió el nombre de Isla del Carmen.

\section{LAS PIRATERÍAS EN EL NUEVO MUNDO}

Muchas fueron las causas que movieron a la piratería americana, pero pueden reducirse a cuatro: 1) la aparición de grandes riquezas en América, principalmente oro y plata; 2) la existencia en Europa de una enorme masa de población pauperizada; 3) la rivalidad política entre los reinos europeos; y 4) la debilidad del imperio ultramarino español. El saqueo por los españoles de los considerables tesoros indígenas durante la conquista y, posteriormente, la aparición de las minas de plata actuaron como un imán para atraer a los desheredados de toda riqueza y a los burgueses aventureros (Pérez Martínez 1937; Lucena Salmoral 1992, 26).

Sin los enormes yacimientos de metales preciosos, la piratería habría tenido otro derrotero, pero el nuevo continente se presentó ante los ojos de la población francesa e inglesa como una tierra inmensamente rica, y no les parecía justo que estuviera acaparada por el reino de España. Las propias Coronas española y portuguesa hicieron concebir a las llamadas Indias Occidentales como un paraíso donde el oro crecía hasta en los árboles. 
Todo ello propició que incluso algunos barones pertenecientes a la nobleza abrazaran la piratería como oficio coyuntural para resarcirse de sus malos negocios -M. M. Postan denomina "gangsterismo" de la nobleza inglesa a la utilización de medios ilegales para recuperar un nivel de ingresos perdido-abandonándola luego para vivir honorablemente. Lo corriente, sin embargo, era hacer de la piratería una fórmula de vida y morir en ella, esperando ese golpe de suerte que no llegaba jamás. La piratería en lo fundamental se nutrió de desheredados y miserables (Jármy Chapa 1983, 43-45; Lucena Salmoral 1992, 26) y solamente unos pocos hombres acaudalados, en calidad de corsarios, se enfocaron en la tajada grande del pastel.

El desarrollo demográfico europeo hizo aumentar peligrosamente el número de desposeídos de bienes, representando una amenaza para la estabilidad de sus gobiernos. Ni el capitalismo comercial, ni las guerras de religión, ni las luchas hegemónicas, pudieron absorberlos, por lo que algunos monarcas de Europa occidental tomaron inteligentemente la decisión de lanzarlos al exterior para que vivieran a costa de los españoles y portugueses hurtándoles sus bienes, quienes previamente habían expoliado a los indígenas americanos.

Junto con aquella palanca que era el pauperismo de la población, no es menos cierto que hubo también quienes piratearon porque les gustaba la aventura, porque creían defender así sus principios religiosos, porque buscaban la libertad, o porque querían perder de vista a los acreedores y hasta a la mujer. "Es curioso observar que muchos famosos piratas eran hombres cultos, pertenecientes a buenas familias y cuyos antecedentes y educación jamás hubieran podido dar lugar a la sospecha de que más tarde se convertirían en ladrones de los mares" (Leydi, Polillo y Giglio 1961, 143).

Para efectuar los viajes trasatlánticos, los europeos contaban, hacia el final del siglo xv, con naves adecuadas para luchar contra el viento en el mar abierto, de maderamen clavado más resistente y aparejo de velas cuadras, que requerían menos número de tripulantes para manejarlo, lo que disminuía considerablemente el problema del avituallamiento. 
Las naves de los descubridores y colonizadores y piratas de los siglos XV y XVI, eran generalmente pequeñas: "la Niña" de Colón tenía sesenta toneladas, la "Pelican" de Drake, cerca de ciento veinte, pero los corsarios armaban flotas comandadas por una o dos naves de cuatrocientas y más toneladas. Eran pequeńas por tres razones: mantener baja la inversión con altas ganancias; asegurar una velocidad mayor y hacer así durar al máximo las provisiones; y el propósito era explorar o navegar próximas a las costas, lo cual implicaba aguas poco profundas y caletas angostas (Jármy Chapa 1987, 31-32). Por cierto, la piratería estimuló grandemente el desarrollo de la tecnología naval.

La tripulación de un barco de este tamaño era de cerca de 25 hombres, esta combinación era fundamental para la duración de una aventura. La tripulación representaba un microcosmos de la sociedad en tierra: un caballero como capitán; el piloto, un profesional; el dueño del navío, un hombre de negocios o su representante; los oficiales y contramaestres eran artesanos hábiles; los más numerosos, un proletariado de marinos algunos de los cuales hacían su primer viaje o eran casi niños. Acerca del marinero común se sabe muy poco, ninguno dejó narración de sus motivos para embarcarse o de sus sentimientos (Jármy Chapa 1987, 32-33).

El hombre común europeo de su época-que solía embarcarse como marinero- era iletrado, ignorante y supersticioso, cuando no, sumamente religioso. Las condiciones en que vivían en tierra, el descontento y el afán de aventura les hacían embarcarse. Seguramente conocían los riesgos: al vivir los marineros en un espacio tan reducido, sucio, infestado de pulgas, piojos y ratas eran presa fácil de la enfermedad. Por esta causa en cada viaje de aventura morían en promedio cinco personas de la tripulación (Jármy Chapa 1983, 45). Los bucaneros representan otra generación, son los hijos de estos primeros piratas aventureros que se fueron quedando en el Caribe.

En cambio los corsarios clásicos -tales como Hawkins, Parker y Drake, por ejemplo- ejercieron la piratería en la modalidad del acecho y del asalto y no se interesaron en el tráfico del palo de tinte, en todo caso, preferían incursionar en el incipiente tráfico de esclavos africanos. El tráfico de materias primas estaba primordialmente en 
manos de corsario-comerciantes menos beligerantes y más directamente ligados con las empresas del ramo industrial textil europeo. Ya que mientras crecía la población en las colonias faltaban hasta los más elementales productos y artículos de primera necesidad cuya producción o elaboración había sido brutalmente impedida por las propias autoridades coloniales. De esta manera comenzó el contrabando, el cual a su vez facilitaba a las potencias enemigas de Espańa surtirse de materias primas que necesitaban para su naciente industria manufacturera (Pérez Martínez 1937, 9).

\section{Conclusión}

La tala y el robo de árboles del palo de tinte en la Laguna, como ocurrió en Belice, constituyen una modalidad de la piratería americana con grandes alcances económicos así como políticos (Contreras Sánchez 1987). La depredación del medio ambiente en algunas regiones tuvo consecuencias severas, en este caso estudiado no fue así. La deforestación de los ingleses parece no haber mermado significativamente el enorme potencial de los tintales de la Laguna.

La hegemonía inglesa del siglo xviı facilitó el apogeo de la extracción pirática del palo de tinte en estos inmensos tintales de la Laguna. Incluso después que los ingleses se habían comprometido combatir la piratería, "después de los tratados de Madrid (1671), las Cortes Españolas informaron al virrey de la Nueva España que el comercio del palo de tinte en Europa había aumentado y que era más lo que sacaban los ingleses de la Isla (de Tris) que lo que sacaban las naves espańolas de Campeche" (Bolívar 2000, 33). Y si bien la ineficacia e incompetencia militar española es un factor de peso que no debe omitirse, la concurrencia de varios otros factores ligados a la expansión del capitalismo comercial en la escala mundial es definitiva.

Las características ambientales de los tintales no era nada hospitalaria. Técnicamente era imposible obtener la hematoxilina in situ. Por lo cual, la explotación del palo de tinte por los ingleses aunque no dio lugar a colonización, enlazó económicamente tres espacios (Wallerstein 1999) que a primera vista parecen separados. El espacio central o sea la ciudad de la manufactura textil que la consumía; el 
espacio de la semiperiferia, o sea Jamaica en el que concentraba la producción del Caribe; y el espacio regional, o sea la Laguna que la producía.

Si miramos un instante hacia la otra cara, vemos que los colonizadores españoles buscaron enriquecerse rápida y fácilmente, lo cual explica que la Laguna no les interesara a los primeros encomenderos. Era una región considerada improductiva, una extensión de los pantanos de Tabasco. El contingente pirático tenía otra mentalidad. La vegetación de las costas caribeñas y del Golfo de México cobró significado económico y fue utilizada por unas personas y agentes con una mentalidad aventurera y burguesa, guiados por el interés de obtener dinero, ganancias o simplemente productos de consumo inmediato. El móvil de la piratería forestal fue la ganancia y el enriquecimiento, con base en el esfuerzo individual y no en el asalto o el crimen. Por todo lo anterior considero que esta modalidad pirática merece, por separado, una valoración teórica de sus alcances económicos y políticos.

Esta piratería forestal en condiciones bastante difíciles, el trabajo duro y organizado, el riesgo que tomaban los agentes intervinientes, ilustra sobre todo lo que Wallerstein llama el sistema economíamundo, porque no muy lejos de la Laguna, en Campeche, la iniciativa privada espańola no se enfrentó al mercado, porque no encontró terreno económico donde actuar y desarrollarse. El incipiente capitalismo español del siglo Xvi fue detenido en seco, con la reglamentación para fortalecer el monopolio imperial. La férrea intromisión de la Corona espańola en la economía conllevó un proceso decadente de la iniciativa privada. En cambio, con el tipo de acciones, como las aquí narradas, los piratas y corsarios ayudaron eficazmente al desarrollo de la modernidad capitalista de sus países y éste no es un tema menor o colateral.

\section{BiBLIOGRAFÍA}

Antochiw, Michel, Artillerías y fortificaciones en la Península de Yucatán. Siglo XVIII, Campeche, Gobierno Constitucional del Estado de Campeche, 2004. 
APestegui, Cruz, Los ladrones del mar. Piratas en el caribe: corsarios, filibusteros y bucaneros 1493-1700, España, Lunwerg Editores, 2000.

Bolívar Aguilar, Juan José, Monografía del municipio del Carmen, México, Universidad Autónoma de Ciudad del Carmen, Colección Material Didáctico, 2000.

Compendio de historia de Ciudad del Carmen, Campeche, C. Carmen Campeche, Ed. Contrastes, 2000a.

Bracamonte y Sosa, Pedro, La conquista inconclusa de Yucatán. Los mayas de la montaña, 1560-1680, México, Ciesas, Miguel Ángel Porrúa, 2001.

Calderón Quijano, José A., Belice, 1663(?)-1821. Historia de los asentamientos británicos del rio valis hasta la independencia de Hispanoamérica, Sevilla, Escuela de Estudios Hispanoamericanos de la Universidad de Sevilla, 1944.

Cantarell Alejandro, Daniel, Recopilación histórica de la Isla del Carmen, México, Isla del Carmen Campeche, 2004.

Contreras Sánchez, Alicia del Carmen, "El palo de tinte, motivo de un conflicto entre dos naciones, 1670-1802", Historia Mexicana, vol. xxxviI, julio-septiembre, núm. 1, 1987, 49-74.

, Historia de una tintórea olvidada. El proceso de explotación y circulación del palo de tinte 1750-1807, Mérida, Universidad Autónoma de Yucatán, 1990.

Cruz, Francisco Santiago, Los piratas del Golfo de México, México, Editorial Jus, 1962.

DampIer, William, Dos viajes a Campeche, México, Miguel Ángel Porrúa, 2004.

García Bernal, Manuela Cristina, Campeche y el comercio atlántico yucateco, (1561-1625), Campeche, Conaculta Campeche, Gobierno del Estado de Campeche, 2006.

Gargallo, Francesca y Adalberto Santana, comps., Belice: sus fronteras y destino, México, Universidad Nacional Autónoma de México, 1993.

Jármy Chapa, Martha de, La expansión española hacia América y el Océano Pacifico, México, Distribuciones Fontamara, 1987. , Un eslabón perdido en la historia, México, Universidad Nacional Autónoma de México, 1983. 
Justo Sierra, Carlos, Breve historia de Campeche, México, El Colegio de México, 1998.

Juárez Moreno, Juan, Piratas y corsarios en Veracruz y Campeche, Sevilla, Escuela de Estudios Hispano-Americanos de Sevilla, 1972.

LeYDI, Roberto y otros, Piratas, corsarios y flibusteros, Barcelona España, Editorial Maucci, 1961.

López Zea, Leopoldo Daniel, Piratas del Caribe y Mar del Sur en el siglo XVI (1497-1603), México, Universidad Nacional Autónoma de México, 2003.

Lucena Salmoral, Manuel, Piratas, bucaneros, filibusteros y corsarios en América, Madrid España, Ediciones MAPFRE, 1992

Millet CÁmara, Luis, "Yucatán: su entrada al mercado mundial de materias primas", Sociedad, estructura agraria y Estado en Yucatán, Othón Baños Ramírez, ed., Mérida Yucatán, Ediciones de la Universidad Autónoma de Yucatán, 1990, 21-44,

Mota, Francisco, Piratas en el Caribe, La Habana, Casa de las Américas, 1984.

Pérez Martínez, Héctor, Piraterías en Campeche (Siglos XVI, XVII y XVIII), México, Porrúa Hnos. y Cía., 1937.

Piña Chan, Román, Campeche durante el periodo colonial, México, Instituto Nacional de Antropología e Historia, 1977.

Rubio Mañé, Ignacio, "Ocupación de la Isla de Términos por los ingleses, 1658-1717”, Boletin del Archivo General de la Nación, vol. 24, núm. 2, 1953, 296-330.

Sales Gutiérrez, Carlos, Campeche. Apuntes económicos y sociales, México, Talleres de fototipo, 1996.

Sosa S., Federico, Datos para la historia del Carmen, México, H. Ayuntamiento del Carmen Campeche, 1984.

VAdillo López, Claudio, La región del palo de tinte: El partido del Carmen, Campeche 1821-1857, Campeche, Fondo para la Cultura y las Artes Campeche, 1994.

, Campeche: sociedad, economía, política y cultura, México, Universidad Nacional Autónoma de México, 2000.

Vargas, Hugo, Piratas en el Caribe, México, Consejo Nacional para la Cultura y las Artes, 2007.

Vega Alí, Rafael, "Prólogo" en Efraín Caldera Noriega, comp., El 
Carmen. Imágenes de ayer, Ciudad del Carmen, Ayuntamiento Constitucional de El Carmen, 2001.

VICTORIa OJEDA, Jorge, La piratería en la América española, siglos XVI al XIX: una transición de intereses, México, Gobierno del Estado de Campeche, Conaculta, 2003.

WALLERSTEIN, Immanuel, El moderno sistema mundial. La agricultura capitalista y los origenes de la economía-mundo europea en el siglo XVI, vol. I, México, Siglo XXI Editores, 1999.

FeCHA DE RECEPCión DEL ARTíCULO: 9 de septiembre de 2010 FECHA DE ACEPTACIÓN Y RECEPCIÓN DE LA VERSIÓN FINAL: 11 de julio de 2011 